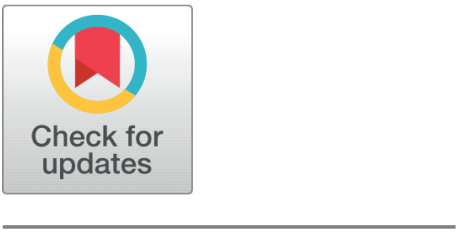

OPEn ACCESS

Received: 11.12.2021

Accepted: 08.01.2022

Published: 31.01 .2022

Citation: Moreno RB, Solar NJB (2022) Development and Sensory Evaluation of Peanut-Pine Butterscotch Bar. Indian Journal of Science and Technology 15(3): 107-114. https://doi.org/ 10.17485/IJST/v15i3.2089

* Corresponding author. raymund.moreno@wvsu.edu.ph

Funding: None

Competing Interests: None

Copyright: (c) 2022 Moreno \& Solar. This is an open access article distributed under the terms of the Creative Commons Attribution License, which permits unrestricted use, distribution, and reproduction in any medium, provided the original author and source are credited.

Published By Indian Society for Education and Environment (iSee)

ISSN

Print: 0974-6846

Electronic: 0974-5645

\section{Development and Sensory Evaluation of Peanut-Pine Butterscotch Bar}

\author{
Raymund B Moreno ${ }^{1 *}$, Nick John B Solar ${ }^{2}$ \\ 1 Assistant Professor of Food Technology and Hospitality Management, College of Business \\ and Management, West Visayas State University, Calinog, Iloilo, Philippines \\ 2 Research Coordinator, Department of Education, Division of Iloilo, Philippines
}

\section{Abstract}

Objectives: This study looked at the sensory acceptance of butterscotch enriched with sweetened pineapple and finely chopped peanuts as to the appearance, scent, taste, texture, and overall acceptability, as well as its nutritional value, proximate composition, packaging, and labeling. Methods: In the trials, five treatments were used: four of which included sweetened pineapple and peanuts in varying quantities, and one treatment served as the control variable, hence, it did not have sweetened pineapple or peanuts. The study's respondents were ten West Visayas State University (WVSU)-Calinog Campus teachers and staff, ten WVSU-Calinog Campus Food Technology and Bachelor of Science in Hotel and Restaurant Management (BSHRM) students, and ten food enthusiasts who were chosen through purposive sampling. A 9-point Hedonic Scale was used for the sensory evaluation of the finished products. Findings: Treatment $\mathrm{C}$ proximate composition evaluation showed these results - moisture content (17.31\%), ash content (1.04\%), crude protein (6.60\%), total fat $(24.34 \%)$ and carbohydrate (50.71\%). Energy taken from Treatment $C$ is $448 \mathrm{kcal} / 100 \mathrm{~g}$. Sensory evaluation of Treatment $C$ is liked extremely. With packaging and labeling designed, butterscotch cookies with 74 grams of finely chopped peanuts and 111 grams of sweetened pineapple enrichment could be a potential product that can be marketed as a delectable snack or dessert with a higher nutritional value. Novelty: The novelty of this research covers the development of a new product out of peanut and pineapple that will compete with the existing cookies products in the market.

Keywords: Development; butterscotch; sweetened pineapple; chopped peanuts; sensory acceptance

\section{Introduction}

Due to the hustle and bustle in developing countries recently changes in the lifestyles and socioeconomic conditions, convenience snack consumption is on the rise ${ }^{(1)}$. The replacement of wheat flour with the fiber content can be increased by mixing it with high-fiber flour in making cookies ${ }^{(2)}$.

Peanuts, on the other hand, are edible seeds of a legume that are commonly referred to as "groundnuts". The second-largest country for peanut production in the world is 
India. It has an annual production of around 7,131 billion metric tons ${ }^{(3)}$. The peanut (Arachis hypogaea) is classified as a pea and is a member of the bean/legume family (fabaceae). Despite being a legume, because of its high oil content, it is usually identified as an oilseed. Peanuts are a high-protein, high-oil, and high-fiber food ${ }^{(4)}$. In addition to oil, peanuts are used to make as an ingredient in some dishes. Peanut cultivars come in thousands of varieties. Several cultivar groups are adopted for specific uses due to the differences in various aspects such as flavor, size content of oil, shape, and disease resistance ${ }^{(5)}$.

Pineapple is a delicious tropical fruit with high juiciness. The Spaniards, during the galleon trade, brought it to the Philippines. These by ships from Mexico carried many plants and products from America; among them was the pineapple. Aside from having a bright tropical taste, it has numerous proven health advantages. Pineapple is used as fresh fruit, for canning, and juice concentrates, all of which have certain size, color, scent, shape and flavor criteria ${ }^{(6)}$. It shines not only because of its inherent sweetness, but also due to its nutritional contents ${ }^{(7)}$.

In most desserts and salads, ripe pineapples are used. This may be in the form of locally produced delicacies or processed into jams and juices. Pineapple nutrients including bromelain, vitamin A, and vitamin B1 are excellent materials for treating a variety of ailments. In addition, pineapple contains citric acid, which aids in fat elimination and weight loss during a diet regimen. According to ${ }^{(8)}$, two-thirds of pineapple is sugar, such as sucrose, with the rest are glucose and fructose, and sucrose approximately contains the two-thirds of sugar content ${ }^{(9)}$.

The link between several processed foods and obesity has been hotly debated in the food industry. The main goal is to provide good health to the population through the products ${ }^{(10)}$. The baking industry has developed attractive and striking presentations to reach more consumers as well as improvements in its nutritional content ${ }^{(11)}$. Adding nutritional value to a food product by blending flours is a viable option ${ }^{(12)}$. Cookies may be fortified or enhanced with cereals or other ingredients ${ }^{(13)}$, resulting in a high-nutrient food ${ }^{(14)}$. Consumption of functional foods or fortified foods may assist in the maintenance of a healthy diet.

The usage of peanuts and pineapple as ingredients in cuisines are limited in the Philippines, hence, it requires further study about its composition and other techniques of exploitation and value addition due to its high perishable nature. The goal of this research is to conduct sensory tests, economic viability on butterscotch cookies that have been supplemented with sweetened pineapple and finely chopped peanuts. Furthermore, the nutritional value, as well as proximate analysis, packaging and labeling, will be investigated as well.

\section{Methods}

\subsection{Research Design}

This research had employed an experimental technique. It aimed to find the sensory acceptability of butterscotch cookies enriched with sweetened pineapple and finely chopped peanuts. This has provided them the convenience of being able to manage variables to eventually narrow down and come up with excellent results. Nutritional and proximate analyses were also done because aside from deciphering the nutritional composition of foods, these processes aid in generating fair market competitions among food producers, thus making it very advantageous for the general consumers.

\subsection{Material Preparation}

The methods were carefully thought and executed according to industry standards. Materials and ingredients are of high quality and were handled with utmost consideration when it comes to sanitation.

Locally grown peanuts and pineapple at ripening stage were bought at Calinog Public Market prior to the experiment. Pineapple was manually sliced, peeled and washed. The peeled fruit was chopped using a kitchen knife and it was blended using the kitchen blender. Blended pineapple was kept in a sanitized container for further use.

\subsection{Proximate and Nutritional Analyses}

Official Methods of Analysis International were used to undertake proximate analysis independently. An indirect method Association of Official Analytical Chemists ${ }^{(15)}$ was used to determine moisture content, and the Kjeldahl Method was used to determine crude protein, which involves team distillation and block digestion; total fat was determined using the Acid Hydrolysis and Solvent Extraction method while the ash content was determined using the Direct Method and the Soxtec System HT2 as the solvent ${ }^{(16)}$. 


\subsection{Sensory Evaluation}

Putting emphasis on precision and accuracy, as well as to ensure authentic results, the Sensory Evaluation of the finished goods were graded using a 9-point Hedonic scale. To maximize its effectivity, the evaluation was conducted on November 6, 2020 at 1:00 - 2:00 o'clock pm by the selected 30 panelist from the WVSU-Calinog Campus's Food Technology Department to participate. To make sure that they fit the purpose, respondents included were 10 each (food enthusiasts, food technology students and faculty members). Panelists had directed to have their mouth rinse with water in between evaluations for more accurate results.

\subsection{Statistical Analysis}

A very essential technique in data treatment, statistical analysis is very valuable in the determination of the suitability of a new and innovative product. Its results are definitive of possible sales, demand and is a guide for manufacturers on when to do product launch.

To determine the product's sensory level of acceptance as to appearance, scent, texture, taste, and overall acceptability, mean was used. For appearance, scent, taste, texture, and general acceptability. The procedures were not only compliant to the standards set but were meticulously performed with precision and attention to details. Materials and ingredients were inspected to guarantee excellent quality attributes of the finished products.

The 9-point hedonic scale was used: 8.12 - 9.00 (Like Extremely), 7.23 - 8.11 (Like Very Much), 6.34 - 7.22 (Like Moderately), 5.45 - 6.33 (Like Slightly), 4.56 - 5.54 (Neither Like nor Dislike), 3.67 - 4.55 (Dislike Slightly), 2.78 - 3.66 (Dislike Moderately), 1.89 - 2.77 (Dislike Very Much), 1.00 - 1.88 (Dislike Extremely) ${ }^{(17)}$.

\section{Results and Discussion}

Taking into great consideration its target beneficiary, the researchers identified which element of the research is important as this will also determine how the recipe will be standardized. A clearer perspective on what flavors will be essential to the dish, availability of key ingredients and cooking/ preparation methods are the requirements in order to come up with it.

Table 1. Formulation of butterscotch cookies enriched with sweetened pineapple and finely chopped peanuts

\begin{tabular}{llllll}
\hline \multirow{2}{*}{ Ingredients } & \multicolumn{9}{l}{ Treatments } \\
\cline { 2 - 6 } & $\mathrm{A}$ & $\mathrm{B}$ & $\mathrm{C}$ & $\mathrm{D}$ & $\mathrm{E}$ \\
\cline { 2 - 6 } & Qty. & Qty. & Qty. & Qty. & Qty. \\
\hline All Purpose Flour (g) & 256 & 256 & 256 & 256 & 256 \\
Baking powder (g) & 5 & 5 & 5 & 5 & 5 \\
Baking soda (g) & 3 & 3 & 3 & 3 & 3 \\
Butter (g) & 113 & 113 & 113 & 113 & 113 \\
Brown sugar (g) & 300 & 300 & 300 & 300 & 300 \\
Glucose (g) & 185 & 185 & 185 & 185 & 185 \\
Vanilla (g) & 5 & 5 & 5 & 5 & 5 \\
Eggs (g) & 100 & 100 & 100 & 100 & 100 \\
Sweetened Pineapple (g) & 0 & 60 & 120 & 180 & 240 \\
Ground Peanuts (g) & 150 & 112.50 & 75.00 & 37.5 & 0 \\
\hline
\end{tabular}

Table 1 shows the different ingredients of the butterscotch cookies. The varying amount of sweetened pineapple and finely chopped peanuts are also indicated. Complimentary amounts of the sweetened pineapple and finely chopped peanuts are further reflected in the table as an enriching agent for butterscotch cookies.

Color is unquestionably one of the most appealing elements of food and is an essential quality parameter influencing the purchase decision of consumers ${ }^{(18)}$. Relative to this, Table 2 shows that the obtained mean of Treatment A was 7.37; Treatment $B$ was 7.97; Treatment $C$ was 7.97; Treatment $D$ was 7.40 and Treatment $E$ was 7.70. This signifies that the respondents rated Treatments A, B, C, D, \& E as "Like Very Much" as to appearance. Treatment C received an average of 8.30, indicating that the respondents "Like Extremely". This supports the results of the study of ${ }^{(19)}$ on that the closeness of look and color indicates that it is the most important factor in the determination of appearance. In this research, the cookies prepared turned out acceptable and essentially, encouraged the use of materials that is endemic to the place of research. 
Table 2. Mean ratings of the sensory acceptability level of butterscotch enriched with sweetened pineapple and finely chopped peanuts in various proportions in terms of appearance

\begin{tabular}{lll}
\hline Proportions & Mean & Description \\
\hline Treatment A (150 g ground peanuts without sweetened pineapple \& other ingredients) & 7.37 & Like Very Much \\
Treatment B (112.5 g ground peanuts -60 g sweetened pineapple \& other ingredients) & 7.97 & Like Very Much \\
Treatment C (75 g ground peanuts - 120 g sweetened pineapple and other ingredients) & 8.30 & Like Extremely \\
Treatment D (37.5 g ground peanuts -180 g sweetened pineapple and other ingredients) & 7.40 & Like Very Much \\
Treatment E (240 g sweetened pineapple without ground peanuts and other ingredients) & 7.70 & Like Very Much \\
\hline
\end{tabular}

Table 3. Mean ratings of the sensory acceptability level of butterscotch enriched with sweetened pineapple and finely chopped peanuts in various proportions as to Scent

\begin{tabular}{lll}
\hline Proportions & Mean & Description \\
\hline Treatment A (150 g ground peanuts without sweetened pineapple \& other ingredients) & 7.37 & Like Very Much \\
Treatment B (112.5 g ground peanuts -60 g sweetened pineapple \& other ingredients) & 7.87 & Like Very Much \\
Treatment C (75 g ground peanuts - 120 g sweetened pineapple and other ingredients) & 8.10 & Like Extremely \\
Treatment D (37.5 g ground peanuts -180 g sweetened pineapple and other ingredients) & 8.00 & Like Very Much \\
Treatment E (240 g sweetened pineapple without ground peanuts and other ingredients) & 7.90 & Like Very Much \\
\hline
\end{tabular}

An aroma is an important characteristic attribute of food, and it can be used as an important indicator of monitoring food quality ${ }^{(20)}$, it treated the modifying effects of aroma (intrinsic) on the perception of sweetness as something that is already given. So, it focused more on how intrinsic factors as well as extrinsic factors for foods and beverages enhance the perception of sweetness. The results are very useful to food producers because these multiple sensory cues will pave the way for them to create more effective sugar-reduced products which are basically a healthier option but still not compromising consumer satisfaction.

Now, going back to the research, Table 3 shows that Treatment A was 7.37; Treatment B was 7.87; Treatment D was 8.00 and Treatment $\mathrm{E}$ was 7.90. These findings mean that Treatments A, B, D and E were "Like Very Much" by the respondents in terms of aroma. Treatment $\mathrm{C}$ obtained a mean of 8.10 that means "Like Extremely" by the respondents. This clearly meant that the aroma coming from the right amount of pineapple and peanuts is a determining factor in the results yielded.

Table 4. Mean ratings of the sensory acceptability level of butterscotch enriched with sweetened pineapple and finely chopped peanuts in various proportions as to Texture

\begin{tabular}{lll}
\hline Proportions & Mean & Description \\
\hline Treatment A (150 g ground peanuts without sweetened pineapple \& other ingredients) & 7.40 & Like Very Much \\
Treatment B (112.5 g ground peanuts -60 g sweetened pineapple \& other ingredients) & 7.87 & Like Very Much \\
Treatment C (75 g ground peanuts - 120 g sweetened pineapple and other ingredients) & 7.93 & Like Very Much \\
Treatment D (37.5 g ground peanuts -180 g sweetened pineapple and other ingredients) & 7.37 & Like Very Much \\
Treatment E (240 g sweetened pineapple without ground peanuts and other ingredients) & 7.73 & Like Very Much \\
\hline
\end{tabular}

Texture is the physical characteristics of food that is generally perceived by the sense of touch. In a study conducted by Paragados ${ }^{(21)}$, it evaluated the acceptance of cookies in terms of texture, which contains canistel as replacement to wheat flour. Further, it concluded that high acceptance in texture is because of the crispiness and tenderness of the canistel flour with the right proportion (50\%).

The next step would be to assess the texture of the product relevant to its sensory acceptability. Texture refers to the way a surface feels and looks, as well as its smoothness or roughness and is the substance's structure when it's felt, touched, or chewed in food. The physical and chemical interaction of a substance in the mouth, on the other hand, is known as mouth feel. It's a subset of food rheology that covers many aspects of food testing and evaluation.

As per the results, in Table 4, it shows that the obtained mean of Treatment A was 7.40; Treatment B was 7.87; Treatment $\mathrm{C}$ was 7.93; Treatment $\mathrm{D}$ was 7.37 and Treatment $\mathrm{E}$ was 7.73 . This means that the respondents rated treatment $\mathrm{A}, \mathrm{B}, \mathrm{C}, \mathrm{D}, \mathrm{\&}$ $\mathrm{E}$ as "Like Very Much" as to texture, with Treatment $\mathrm{C}$ getting the highest score. The right proportion of the pineapple and crushed peanuts resulted to a moist yet firm butterscotch which majority finding it very appealing with just the right amount of smoothness. 
Table 5. Mean ratings of the sensory acceptability level of butterscotch enriched with sweetened pineapple and finely chopped peanuts in various proportions as to Taste

\begin{tabular}{lll}
\hline Proportions & Mean & Description \\
\hline Treatment A (150 g ground peanuts without sweetened pineapple \& other ingredients) & 7.47 & Like Very Much \\
Treatment B (112.5 g ground peanuts -60 g sweetened pineapple \& other ingredients) & 8.17 & Like Extremely \\
Treatment C (75 g ground peanuts - 120 g sweetened pineapple and other ingredients) & 8.23 & Like Extremely \\
Treatment D (37.5 g ground peanuts -180 g sweetened pineapple and other ingredients) & 8.47 & Like Extremely \\
Treatment E (240 g sweetened pineapple without ground peanuts and other ingredients) & 8.07 & Like Very Much \\
\hline
\end{tabular}

Taste influences food selection, and better apprehension of the links between food flavor, the taste preferences of the person, food choices, and intakes will help understand why some people choose and take foods which are not healthy ${ }^{(7)}$. Anything small amount can be eaten or consumed to assess the influence on sensory receptors. In a study done by ${ }^{(22)}$, it turned out that consumer preference is not absolute, and that their liking decreases over time and they may crave for different types of taste especially in the initial and final part. That is why, in this research, after doing the taste test, the panelists are directed to rinse their mouths with water after evaluating one sample treatment.

Table 5 says a lot about how coming up with the right kind of blend is important in food preparation. In here, the mean of Treatment A was 7.47 and Treatment E was 7.07. This means that Treatments A and E were "Like Very Much" while Treatments B obtained a mean of 8.17 , Treatment $C$ had a mean of 8.23 and D had a mean of 8.47 were "Like Extremely" and it is not surprising to have this result since the amount of ground peanuts complemented the sweetness of the crushed pineapple, thereby creating a palatable sensation to those who tasted it.

Table 6. Mean ratings of the sensory acceptability level of butterscotch enriched with sweetened pineapple and finely chopped peanuts in different proportions as to General Acceptability

\begin{tabular}{lll}
\hline Proportions & Mean & Description \\
\hline Treatment A (150 g ground peanuts without sweetened pineapple \& other ingredients) & 7.53 & Like Very Much \\
Treatment B (112.5 g ground peanuts -60 g sweetened pineapple \& other ingredients) & 8.13 & Like Extremely \\
Treatment C (75 g ground peanuts - 120 g sweetened pineapple and other ingredients) & 8.57 & Like Extremely \\
Treatment D (37.5 g ground peanuts -180 g sweetened pineapple and other ingredients) & 8.07 & Like Very Much \\
Treatment E (240 g sweetened pineapple without ground peanuts and other ingredients) & 7.97 & Like Very Much \\
\hline
\end{tabular}

Food acceptance or rejection is entirely dependent on whether it meets the expectations and needs of the consumer ${ }^{(23)}$. It is generally acceptable when something is deemed socially acceptable or within the boundaries of what is proper, or when something is tolerated but not necessarily desirable. Food acceptability is affected by a different factors, including the person, the food, and the context in which the food is consumed. Treatments A, D and $\mathrm{E}$ had means of 7.53, 8.07, and 7.97, respectively and is shown in Table 6. This means that the respondents "Like Very Much" Treatments A, D, and E, while Treatment B had a mean of 8.13 and as supported by previous elements of this sensory evaluation, the big winner is Treatment $\mathrm{C}$, which had a mean of 8.57 and were "Like Extremely" in terms of general acceptability.

The results shows that the cost of each treatment are 96.75 pesos, 103.750 pesos, 103.75 pesos, 103.75 pesos and 96.75 pesos for treatments A, B, C, D and E, respectively. There is a very minimal difference in the price for each individual treatment even if they all have varying proportions of the sweetened pineapple and finely chopped peanuts. Therefore, sweetened pineapple and finely chopped peanuts are very good enhancing agent for food and is cost-efficient.

Table 8 shows the proximate composition of butterscotch cookies enriched with sweetened pineapple and finely chopped peanuts. The moisture and carbohydrates increased with increase in the sweetened pineapple enrichment in the peanutpineapple in butterscotch cookies mixture. The value of ash, crude protein, total fat and energy decreased gradually to the lowest value with the decrease in the amount finely chopped peanuts enrichment in the peanut-pineapple in butterscotch cookies mixture.

Table 9 shows the nutritional value of butterscotch cookies enriched with sweetened pineapple and finely chopped peanuts for every 25 grams serving and one piece per pack. The calories and its Recommended Energy and Nutrient Intake (RENI), calories from fat, total fat and the protein content and its RENI decreased as the amount of finely chopped peanuts decreased in the enrichment of the peanut-pineapple in the butterscotch cookies mixture. The value of total carbohydrates increased gradually to the highest value with the increase in the sweetened pineapple enrichment in the peanut-pineapple in Butterscotch cookies mixture. The products were analyzed at the Department of Science and Technology VI (DOST), Iloilo City, Philippines. 
Table 7. Raw materials cost analysis

\begin{tabular}{|c|c|c|c|c|c|c|c|c|c|c|}
\hline \multirow{2}{*}{ Ingredients } & \multicolumn{2}{|l|}{ A } & \multicolumn{2}{|l|}{ B } & \multicolumn{2}{|l|}{$\mathrm{C}$} & \multicolumn{2}{|l|}{$\mathrm{D}$} & \multicolumn{2}{|l|}{$\mathrm{E}$} \\
\hline & Qty. & Cost & Qty. & Cost & Qty. & Cost & Qty. & Cost & Qty. & Cost \\
\hline All Purpose Flour (g) & 256 & 25.00 & 256 & 25.00 & 256 & 25.00 & 256 & 25.00 & 256 & 25.00 \\
\hline Baking powder (g) & 5 & 0.25 & 5 & 0.25 & 5 & 0.25 & 5 & 0.25 & 5 & 0.25 \\
\hline Baking soda (g) & 3 & 0.25 & 3 & 0.25 & 3 & 0.25 & 3 & 0.25 & 3 & 0.25 \\
\hline Butter (g) & 113 & 22.00 & 113 & 22.00 & 113 & 22.00 & 113 & 22.00 & 113 & 22.00 \\
\hline Brown sugar (g) & 300 & 15.00 & 300 & 15.00 & 300 & 15.00 & 300 & 15.00 & 300 & 15.00 \\
\hline Glucose (g) & 185 & 5.00 & 185 & 5.00 & 185 & 5.00 & 185 & 5.00 & 185 & 5.00 \\
\hline Vanilla (g) & 5 & 0.25 & 5 & 0.25 & 5 & 0.25 & 5 & 0.25 & 5 & 0.25 \\
\hline Eggs (g) & 100 & 14.00 & 100 & 14.00 & 100 & 14.00 & 100 & 14.00 & 100 & 14.00 \\
\hline Sweetened Pineapple & 0 & 0.00 & 60 & 9.00 & 120 & 11.00 & 180 & 13.00 & 240 & 15.00 \\
\hline Ground Peanuts & 150 & 15.00 & 112.50 & 13.00 & 75.00 & 11.00 & 37.5 & 9.00 & 0 & 0.00 \\
\hline $\begin{array}{l}\text { Total Cost No. of Yield: } 48 \text { pcs Cost per piece: } \mathrm{P} \\
5.00\end{array}$ & & 96.75 & & 103.75 & & 103.75 & & 103.75 & & 96.75 \\
\hline
\end{tabular}

Table 8. Proximate composition evaluation of butterscotch enriched with sweetened pineapple and finely chopped peanuts in different treatments (14 days)

\begin{tabular}{lllllll}
\hline Treatment & Moisture (\%) & Ash (\%) & Crude Protein (\%) & Total Fat (\%) & Carbohydrates (\%) & Energy (kcal/100g) \\
\hline A & 11.85 & 1.33 & 9.54 & 30.77 & 46.51 & 501 \\
B & 17.03 & 1.12 & 7.45 & 27.96 & 46.44 & 467 \\
C & 17.31 & 1.04 & 6.60 & 24.34 & 50.71 & 448 \\
D & 21.51 & 0.92 & 5.47 & 20.20 & 51.90 & 411 \\
E & 22.76 & 0.79 & 4.55 & 19.56 & 52.34 & 404 \\
\hline
\end{tabular}

Table 9. Nutritional value analysis of butterscotch enriched with sweetened pineapple and finely chopped peanuts in different

\begin{tabular}{|c|c|c|c|c|c|c|c|}
\hline $\begin{array}{l}\text { Treat- } \\
\text { ment }\end{array}$ & $\begin{array}{l}\text { Calories } \\
\text { (kcal) }\end{array}$ & $\begin{array}{l}\text { RENI } \\
(\%)\end{array}$ & $\begin{array}{l}\text { Calories from Fat } \\
(\mathrm{kcal})\end{array}$ & $\begin{array}{l}\text { Total Fat } \\
(\mathrm{g})\end{array}$ & $\begin{array}{l}\text { Total Carbohydrates } \\
(\mathrm{g})\end{array}$ & $\begin{array}{l}\text { Protein } \\
(\mathrm{g})\end{array}$ & $\begin{array}{l}\text { RENI } \\
(\%)\end{array}$ \\
\hline \multirow[t]{2}{*}{$\mathrm{A}$} & 130 & 5 & 70 & 8 & 12 & 2 & 4 \\
\hline & 120 & 5 & 60 & 7 & 12 & 2 & 3 \\
\hline C & 110 & 4 & 50 & 6 & 13 & 2 & 2 \\
\hline $\mathrm{D}$ & 100 & 4 & 45 & 5 & 13 & 1 & 2 \\
\hline $\mathrm{E}$ & 100 & 4 & 45 & 5 & 13 & 1 & 2 \\
\hline
\end{tabular}

Serving size: 25 grams, No. of serving per pack: 1

\subsection{Design and label details}

Basically, it is important to know and identify what are buying. If a container is not labeled, then it may find hard to determine which is which, say, in the case of canned goods where almost all similar products are stored in almost identical cans. Peanut products' oxidative stability has also been shown to be influenced by packaging material and storage temperature ${ }^{(24)}$.

Label on the products will help buyers know the nutritional content of the product. It is also to comply and adhere to existing laws in the country. According to Republic Act No. 7394 or the Philippine Consumer Act, marking and labeling, whether manufactured locally or imported, should have essential information.

On the marketing side, labels can be used to display brand and promote the contents to a target group of consumers. The uniqueness allows easy identification and because of consistent branding, there will be product or name recall, which is the goal of every company - to become a household brand.

With this product, the researchers thought of a simple yet classy-sounding brand name - "Sweet Delights". The design was also consistent with its two main ingredients - peanuts and pineapple. All the other essential requirements; nutritional facts table, 


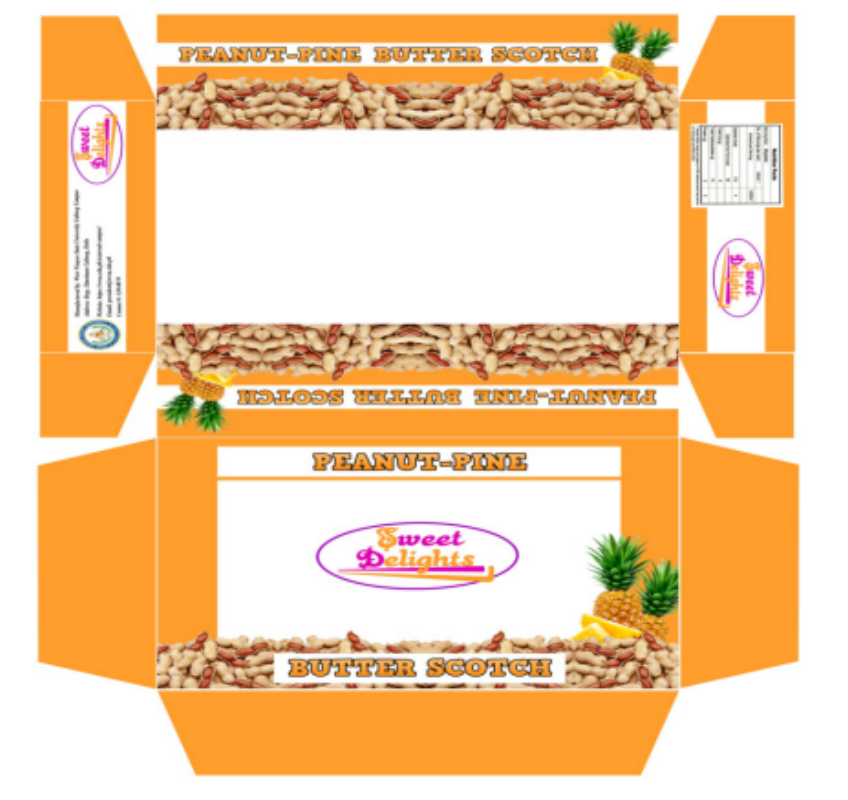

Fig 1. Proposed package and label for butterscotch enriched with sweetened pineapple and finely chopped peanuts in different treatments

list of the ingredients and other information, was included on the packaging, in compliance with existing rules and regulations. To pay homage to manufacturer (place of research), the WVSU logo was also placed in the packaging. The packaging has the following dimensions: $16 \mathrm{~cm}$ (length), $15.5 \mathrm{~cm}$ (width) and $6 \mathrm{~cm}$ (height) which is made of carrier board number 18 paper.

\section{Conclusion and Recommendation}

The innovative butterscotch produced was generally acceptable as snacks or dessert. The sensory evaluation indeed helped us align the recipe and find the preference of the evaluators - in this case, the treatment with 75 grams finely chopped peanuts and 120 grams sweetened pineapple. The "like extremely" rating for appearance, scent, texture and general acceptability meant that this shall be the prototype of future production and gives us the green light to incorporate these ingredients that are generally tastier and healthier due to their nutritious composition.

Proximate analysis and nutritional value show that butterscotch cookies enriched with finely chopped peanuts and sweetened pineapple is a highly nutritious food and should be a top consideration when creating one.

In the food processing industry, shelf-life studies are crucial. Although shelf-life studies have yet to be conducted, the butterscotch cookies treated with finely chopped peanuts and sweetened pineapple samples obtained during this research work may have a good and reasonable shelf life, and this work intends to continue on this study.

Furthermore, it is recommended that the result of this study about the butterscotch cookies with finely chopped peanuts and sweetened pineapple be disseminated to encourage food scientist, housewives, researchers and other food experts to increase its acceptability and nutritional value. Lastly, a parallel study is also recommended using higher levels of finely chopped peanuts and sweetened pineapple to maximize its potential.

\section{References}

1) Abdullah NF, Teo P, Foo L. Ethnic Differences in the Food Intake Patterns and Its Associated Factors of Adolescents in Kelantan, Malaysia. Nutrients. 2016;8(9):551-551. Available from: https://dx.doi.org/10.3390/nu8090551.

2) Jesmin AM, Ruhul AM, Chandra MS. Effect of Pumpkin Powder on Physico- chemical Properties of Cake. International Research Journal of Biological Sciences. 2016;5(4):1-5. Available from: https://www.myfoodresearch.com/uploads/8/4/8/5/84855864/_16_fr-ictmhs-s02_mustika.pdf.

3) ZAFRA M, MOLINA F, PUERTO A. The neural/cephalic phase reflexes in the physiology of nutrition. Neuroscience \& Biobehavioral Reviews. 2006;30(7):1032-1044. Available from: https://dx.doi.org/10.1016/j.neubiorev.2006.03.005.

4) Suchoszek-Lukaniuk K, Jaromin A, Korycińska M, Kozubek A. and others, editor. 2011.

5) Ganorkar PM, Jain RK. Effect of flaxseed incorporation on physical, textural, sensorial and chemical attributes of cookies. International Food Research Journal . 2014;21(4):1515-1521. 
6) Joy P, Pineapple Research Station (Kerala Agricultural University), Vazhakulam-686 670, Muvattupuzha, Ernakulam District, Kerala, India . Benefits and uses of pineapple. Muvattupuzha, Ernakulam District, Kerala, India. 2010.

7) Lawler M. 8 scientific health benefits of pineapple. 2019. Available from: https://www.everydayhealth.com/diet-nutrition/8-reasons-eat-pineapple/.

8) Masniza S, Yih LJ, Roji MS. Chemical composition and sensory analysis of fresh pineapple juice and deacidified pineapple juice using electrodialysis. Regional Symposium on Membrane Science and Technology. 2000.

9) Hossain MF. Nutritional Value and Medicinal Benefits of Pineapple. International Journal of Nutrition and Food Sciences. 2015;4(1):84-84. Available from: https://dx.doi.org/10.11648/j.ijnfs.20150401.22.

10) Vera YC, Rojas NCL, Parra MLM. Elaboración de galletas funcionales con adición de clorofila. Alimentos Hoy. 2016;24(37):49-56.

11) Giuberti G, Gallo A, Fortunati P, Rossi F. Influence of high-amylose maize starch addition on in vitro starch digestibility and sensory characteristics of cookies. Starch - Stärke. 2016;68(5-6):469-475. Available from: https://dx.doi.org/10.1002/star.201500228.

12) Zafra M, Molina F, Peurto A. The neural/cephalic phase reflexes in the physiology of nutrition. Neuroscience \& Biobehavioral Reviews. 2006;30(7):10321044. Available from: https://dx.doi.org/10.1016/j.neubiorev.2006.03.005.

13) Gutierrez KG, Coronel MG, Montes RM, Gómez MNB, Zúñiga EJL. .

14) Giuberti G, Gallo A, Fortunati P, Rossi F. Influence of high-amylose maize starch addition on in vitro starch digestibility and sensory characteristics of cookies. Starch - Stärke. 2016;68(5-6):469-475. Available from: https://dx.doi.org/10.1002/star.201500228.

15) Official Methods of Analysis of AOAC International, 20th Ed. Moisture by gravitric method. Official Method 925.45.. 2016.

16) Official Methods of Analysis of AOAC International, 20th Ed. Ash by gravitric method. Official Method 900.02. 2016.

17) Mcsweeney M, Gambaro A. Chapter Eight - Sensory methods applied to the development of probiotic and prebiotic foods. Advances in Food and Nutrition Research. 2020;94:295-337. Available from: https://doi.org/10.1016/bs.afnr.2020.06.006.

18) Silva. Effect of Babassu (Orbignya phalerata) Mesocarp Flour on the Sensorial Properties and Nutritional Value of Cookies. Journal of Food and Nutrition Research. 2019;7(11):805-809.

19) Sarah JL, Mesnildrey L, Margueritte E, Boisseau M. Laboratory screening of pineapple gennplasm for resistance to the lesion nematode pratylenchus brachyurus. Acta Horticulturae. 1997;42(425):179-186. Available from: https://dx.doi.org/10.17660/actahortic.1997.425.19.

20) Khattab AR, Guirguis HA, Tawfik SM, Farag MA. Cheese ripening: A review on modern technologies towards flavor enhancement, process acceleration and improved quality assessment. Trends in Food Science \& Technology. 2019;88:343-360. Available from: https://dx.doi.org/10.1016/j.tifs.2019.03.009.

21) Paragados D. Acceptability of canistel ( lacuma nervosa a. dc) fruit flour in making cookies. Asia Pacific Journal of Multidisciplinary Research. 2014;2(1).

22) Wang QJ, Mielby LA, Junge JY, Bertelsen AS, Kidmose U, Spence C, et al. The Role of Intrinsic and Extrinsic Sensory Factors in Sweetness Perception of Food and Beverages: A Review. Foods. 2019;8(6):211-211. Available from: https://dx.doi.org/10.3390/foods8060211.

23) Masniza S, Yih LJ, Roji MS. Chemical composition and sensory analysis of fresh pineapple juice and deacidified pineapple juice using electrodialysis. Regional Symposium on Membrane Science and Technology. 2000.

24) Pidatala DPK, Bellmer W, Mcglynn. \& quot;Oxidative Stability of a New Peanut Butter Bite Product \& quot. International Journal of Food Science;2021:1-9. Available from: https://doi.org/10.1155/2021/5528. 